\title{
Pengaruh Perubahan Dimensi Filter-Drier Dan Pipa Kapiler Terhadap Coefficient Of Performance (COP) Mesin Pendingin Kulkas 2 Pintu
}

\author{
Khairul Mustofa $^{1}$, Yohanes Primadiyono ${ }^{2}$ \\ 1,2Program Studi Pendidikan Teknik Elektro Universitas Negeri Semarang \\ Email: ${ }^{1}$ khairulmustofa98@gmail.com, ${ }^{2}$ primasigma@mail.unnes.ac.id
}

\begin{abstract}
Abstrak
Abstrak -- COP pada mesin pendingin digunakan untuk menyatakan unjuk kerja suatu mesin pendingin. Untuk meningkatkan nilai COP pada sistem bisa dilakukan dengan melakukan pengubahan dimensi filter-drier dan pipa kapiler yang digunakan. Dari beberapa literatur yang telah saya baca, saya menemukan bahwa belum ada penelitian yang dilakukan untuk mengetahui pengaruh perubahan dimensi filter-drier dan pipa kapiler terhadap nilai COP yang dihasilkan oleh unit pendingin kulkas 2 pintu. Oleh karena itu penelitian ini dilakukan untuk mengetahui pengaruh perubahan dimensi filter-drier dan pipa kapiler terhadap COP dan konsumsi daya listrik yang dihasilkan unit pendingin kulkas 2 pintu.Metode yang digunakan adalah metode eksperimen yaitu dengan melakukan variasi pada dimensi filter-drier dan pipa kapiler kulkas 2 pintu. Variasi filter-drier yang digunakan adalah filter-drier dengan ukuran $7 \mathrm{~cm}$ dan $9 \mathrm{~cm}$. Sedangkan pipa kapiler yang digunakan adalah dengan diameter 0,31 inchi dan 0,51 inchi dengan panjang masing-masing $200 \mathrm{~cm}$ dan $250 \mathrm{~cm}$. Hasil yang didapat dari penelitian ini menunjukan bahwa nilai COP terbesar didapat pada penggunaan filter-drier $7 \mathrm{~cm}$ dan pipa kapiler berdiameter 0,31 inchi dengan panjang $200 \mathrm{~cm}$ yakni sebesar 2,80. Nilai COP juga terus mengalami penurunan seiring dengan bertambahnya ukuran filter-drier dan pipa kapiler yang digunakan.
\end{abstract}

Kata Kunci: COP, kulkas, filter-drier, pipa kapiler

\begin{abstract}
Abstract -- COP on a cooling machine is used to reveal the performance of a cooling engine. To increase the COP value in the system, it can be done by changing the dimensions of the filter-drier and capillary pipes used. Therefore, this study was conducted to determine the effect of changing the dimensions of the filter-drier and capillary pipe on the COP and the consumption of electrical power produced by the 2door refrigerator unit. The method used was an experimental method, namely by varying the filter drier and capillary tube dimensions of the 2-door refrigerator. Variations of filter driers used were filter driers with sizes $7 \mathrm{~cm}$ and $9 \mathrm{~cm}$. While the capillary pipes used were 0.31 inches in diameter and 0.51 inches in diameter with a length of $200 \mathrm{~cm}$ and $250 \mathrm{~cm}$ respectively. The results obtained from this study indicate that the greatest COP value is obtained when using a $7 \mathrm{~cm}$ filter-drier and a capillary pipe with a diameter of 0.31 inches with a length of $200 \mathrm{~cm}$, which is 2.80 . The COP value also continues to decline as the size of the filter-drier and capillary pipes used increases.
\end{abstract}

Keywords: COP, refrigerator, filter-drier, capillary tube

\section{PENDAHULUAN}

Perkembangan manusia yang semakin besar berdampak pula terhadap perubahan pola kebutuhan hidup mereka. Peningkatan kebutuhan itu terjadi diberbagai sektor yang salah satunya adalah pada sektor sistem pendingin (Fuad \& Putra, 2016). Sistem pendingin ini menyangkut banyak hal, mulai dari proses pendingin ruangan hingga pengawetan makanan. Kulkas merupakan salah satu jenis mesin pendingin yang banyak dipakai oleh masyarakat. Kulkas ini merupakan mesin pendingin yang digunakan untuk menyimpan makanan pada suhu rendah dan juga dalam kondisi beku disesuaikan dengan jenis makanan yang akan disimpan (Yang, 2017). Kulkas pada umumnya terdiri dari bagian 
freezer dan bagian kabin. Bagian freezer digunakan untuk mengawetkan atau membuat es sedangkan bagian kabin berguna untuk penyegar bahan makanan, namun ruang lingkup terbatas hanya untuk keperluan rumah tangga (Daryanto, 2007). Harga kulkas yang cukup terjangkau dan cara pemakaian yang sangat sederhana menjadikan mesin pendingin yang satu ini banyak digemari oleh masyarakat. Selain itu, kebutuhan pengawetan makanan menjadikan kulkas ini seakan menjadi peralatan elektronik yang wajib dimiliki oleh masyarakat

Coefficient of performance (COP) yang merupakan perbandingan antara kapasitas pendinginan dengan daya kompresor menjadi salah satu indikator yang digunakan untuk menilai kinerja mesin pendingin. Nilai COP ini diukur untuk mengetahui seberapa besar penggunaan energi listrik yang dibutuhkan oleh kompresor untuk melakukan suatu proses pendinginan (Zhang et al., 2017).

Coefficient of performance (COP) merupakan indeks prestasi yang menyatakan ukuran keefektifan kerja dari suatu mesin refrigerasi (Stoecker \& Jones, 1992). COP digunakan untuk menyatakan hubungan antara kapasitas pendinginan dengan daya listrik yang diperlukan pada sistem (Oyedepo et al., 2017). Prestasi aktual atau COP aktual merupakan nilai COP sebenarnya didalam sistem refrigerasi yang dihitung menggunakan diagram enthalpi sesuai dengan jenis refrigerant yang digunakan. Nilai prestasi aktual tersebut dapat dihitung dengan menggunakan persamaan berikut ini:

$$
\operatorname{COP}_{\text {aktual }}=\frac{q_{e}}{w}=\frac{h_{1}-h_{4}}{h_{2}-h_{1}}
$$

Keterangan:

$$
\begin{array}{ll}
C O P_{\text {aktual }} & =\text { Nilai COP actual } \\
q_{e} & =\text { Efek refrigerasi }(\mathrm{kJ} / \mathrm{kg}) \\
w & =\text { kerja kompresor }(\mathrm{kJ} / \mathrm{kg})
\end{array}
$$

Salah satu upaya yang dapat dilakukan dalam upaya meningkatkan nilai COP pada sistem adalah dengan melakukan variasi pada dimensi pipa kapiler dan filter-drier pada kulkas. Pipa kapiler dan filterdrier ini merupakan alat ekspansi yang digunakan pada kulkas yang mana berfungsi untuk menurunkan tekanan pada bahan pendingin agar nantinya bahan pendingin tersebut dapat menguap dengan mudah pada evaporator.

Dari beberapa literatur yang telah saya baca, saya menemukan bahwa belum ada penelitian yang dilakukan untuk mengetahui pengaruh perubahan dimensi filter-drier dan pipa kapiler terhadap nilai COP yang dihasilkan oleh unit pendingin kulkas 2 pintu. Tren penelitian yang sering dilakukan oleh para peneliti adalah pada penggunaan beberapa ukuran diameter dan panjang pipa kapiler pada unit pendingin dan pengaruhnya terhadap nilai COP yang dihasilkan oleh unit pendingin tersebut. Dalam literatur yang lain, peneliti menemukan ada satu penelitian yang menguji pengaruh perubahan ukuran filter-drier terhadap nilai COP yang dihasilkan oleh unit pendingin kulkas.

Oleh karena itu penelitian ini dilakukan untuk mengetahui apa pengaruh yang ditimbulkan oleh perubahan dimensi filter-drier dan pipa kapiler terhadap coefficient of performance (COP) yang dihasilkan suatu unit pendingin kulkas 2 pintu.

\section{METODE}

Penelitian ini menggunakan metode penelitian eksperimen. Penelitian eksperimen digunakan untuk mencari hubungan kausal sebab akibat antara variabel bebas dan terikat namun ada manipulasi yang sengaja dikendalikan pada variabel bebasnya. Penelitian yang dilakukan ini menggunakan pendekatan kuantitatif karena bersandar pada pengumpulan dan analisis numerik, menggunakan pengukuran, serta mementingkan hasil (Jakni, 2016). Penelitian ini dilakukan di bengkel CV Sahabat Teknik Pekalongan pada tanggal 21 Oktober 2020 sampai dengan 22 November 2020.

Variasi yang dilakukan dalam penelitian ini adalah dengan penggunaan filter-drier berukuran 7 $\mathrm{cm}$ dan $9 \mathrm{~cm}$ serta pipa kapiler berdiameter 0,31 inchi dan 0,51 inchi dengan panjang masing-masing adalah $200 \mathrm{~cm}$ dan $250 \mathrm{~cm}$. Untuk variasi filter-drier berukuran $9 \mathrm{~cm}$ akan dibuat dengan menambah panjang $2 \mathrm{~cm}$ pada filter-drier normal berukuran 7 $\mathrm{cm}$. Penambahan panjang ini akan dilakukan dengan menggunakan sambungan swagging dan kemudian dilakukan pengelasan pada sambungannya. Adapun untuk diagram alir pada penelitian ini digambarkan pada Gambar 1.

Untuk keperluan pengujian, kulkas yang akan diambil datanya akan dirangkai beberapa peralatan pengujian. Peralatan yang akan dipasang adalah gaugemeter dan juga thermometer. Kedua peralatan tersebut dipasang untuk mengetahui tekanan dan juga suhu pada masing-masing titik pengujian. Untuk rangkaian peralatan pengujian ditunjukan oleh gambar 2 di bawah.

Proses pengujian dalam penelitian ini dilakukan menggunakan kulkas 2 pintu SAMSUNG SR24NMA dengan kapasitas 239 Liter dan jenis refrigerant yang digunakan adalah R134a dengan tekanan pengisian sebesar 8 psig. Rentang waktu 
pengujian adalah 60 menit dengan proses pengambilan data dilakukan setiap 5 menit sekali.

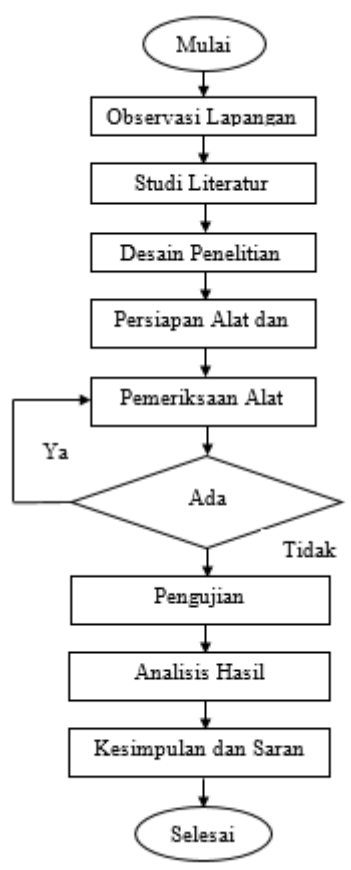

Gambar 1. Diagram Alir Penelitian

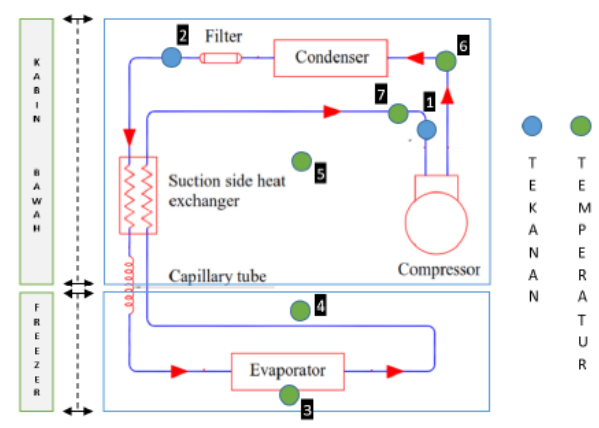

Gambar 2. Skema Peralatan Pengujian

Keterangan:

1. Tekanan suction manifold gauge

2. Tekanan discharge manifold gauge

3. Thermometer evaporasi

4. Thermometer kabin atas

5. Thermometer kabin bawah

6. Thermometer pipa luar discharge

7. Thermometer pipa luar suction

Dalam penelitian ini, data yang diambil untuk mendukung perhitungan adalah sebagai berikut:

- Kuat Arus Running (A)

- Tekanan Suction (psig)

- Tekanan Discharge (psig)

- Temperatur Refrigerant Suction $\left({ }^{\circ} \mathrm{C}\right)$

- Temperatur Refrigerant Discharge $\left({ }^{\circ} \mathrm{C}\right)$

- $\quad$ Temperatur Evaporasi $\left({ }^{\circ} \mathrm{C}\right)$
- Temperatur Kabin Atas $($ Freezer $)\left({ }^{\circ} \mathrm{C}\right)$

- Temperatur Kabin Bawah $\left({ }^{\circ} \mathrm{C}\right)$

- Temperatur Pipa Discharge $\left({ }^{\circ} \mathrm{C}\right)$

- Temperatur Pipa Suction $\left({ }^{\circ} \mathrm{C}\right)$

Untuk pengambilan data temperatur refrigerant dilakukan menggunakan aplikasi Refrigerant Slider pada smartphone. Hal ini bertujuan agar lebih memudahkan kalkulasi hasil yang dieksekusi pada tekanan refrigerant gauge tertentu.

Perhitungan nilai COP pada penelitian ini dilakukan menggunakan software Coolpack versi 1.49. Coolpack merupakan salah satu software yang digunakan untuk mendesain, mensimulasikan dan mengoptimalkan sistem yang berkaitan dengan refrigerant. Software ini merupakan software yang bersifat freeware yang dikembangkan oleh IPU dan Departement Teknik Mesin (MEK) Technical University of Denmark (DTU) sehingga dapat digunakan secara gratis.

\section{HASIL DAN PEMBAHASAN}

Data yang dianalisis merupakan data sampel yang diambil dengan teknik random sampling. Data yang diambil dan dianalisis pada penelitian ini dipilih adalah 2 data diawal, 2 data ditengah, dan 2 data diakhir.

Tabel 1. Data Nilai COP

\begin{tabular}{|c|c|c|c|c|c|c|c|c|}
\hline \multirow{2}{*}{$\begin{array}{c}\text { Menit } \\
\text { ke }\end{array}$} & \multicolumn{4}{|c|}{ Filter-drier 7cm } & \multicolumn{4}{c|}{ Filter-drier 9cm } \\
\cline { 2 - 9 } & $\begin{array}{c}\text { Pipphiler 0,31 } \\
\text { Inchi }\end{array}$ & \multicolumn{2}{c|}{$\begin{array}{c}\text { Pipa kapiler } 0,51 \\
\text { Inchi }\end{array}$} & \multicolumn{2}{c|}{$\begin{array}{c}\text { Pipa Kapiler 0,31 } \\
\text { inchi }\end{array}$} & \multicolumn{2}{c|}{$\begin{array}{c}\text { Pipa Kapiler 0,51 } \\
\text { Inchi }\end{array}$} \\
\cline { 2 - 10 } & $200 \mathrm{~cm}$ & $250 \mathrm{~cm}$ & $200 \mathrm{~cm}$ & $250 \mathrm{~cm}$ & $200 \mathrm{~cm}$ & $250 \mathrm{~cm}$ & $200 \mathrm{~cm}$ & $250 \mathrm{~cm}$ \\
\hline 1 & 3.21 & 2.86 & 2.54 & 2.77 & 2.86 & 2.68 & 2.7 & 2.47 \\
\hline 5 & 2.84 & 2.73 & 2.54 & 2.71 & 2.56 & 2.42 & 2.64 & 2.47 \\
\hline 30 & 2.69 & 2.71 & 2.54 & 2.58 & 2.55 & 2.34 & 2.19 & 2.31 \\
\hline 35 & 2.69 & 2.71 & 2.54 & 2.58 & 2.55 & 2.34 & 2.19 & 2.31 \\
\hline 55 & 2.69 & 2.71 & 2.54 & 2.58 & 2.55 & 2.34 & 2.19 & 2.31 \\
\hline 60 & 2.69 & 2.71 & 2.54 & 2.58 & 2.55 & 2.34 & 2.19 & 2.31 \\
\hline $\begin{array}{c}\text { Rata- } \\
\text { Rata }\end{array}$ & & & & & & & & \\
\hline
\end{tabular}

Tabel 1 merupakan tabel data hasil perhitungan COP menggunakan software Coolpack versi 1.49. Dari tabel 1 telah ditemukan adanya perbedaan nilai COP yang dihasilkan sistem pada masing-masing perlakuan. Nilai rata-rata COP terbesar ada pada penggunaan filter-drier $7 \mathrm{~cm}$ dan pipa kapiler berdiameter 0,31 inchi dengan panjang $200 \mathrm{~cm}$ yakni sebesar 2,80. Dan nilai COP terendah ada pada penggunaan filter-drier $9 \mathrm{~cm}$ pipa kapiler berdiameter 0,51 inchi dengan penjang $200 \mathrm{~cm}$ yakni sebesar 2,35. Perbedaan nilai COP ini terjadi karena adanya perbedaan dimensi pada alat ekspansi yang dalam hal ini adalah filter-drier dan pipa kapiler. Karena adanya perbedaan dimensi ukuran yang dipakai pada alat ekspansi, maka akan berpengaruh pula pada besar gesekan dan percepatan laju aliran refrigerant yang melaluinya. 


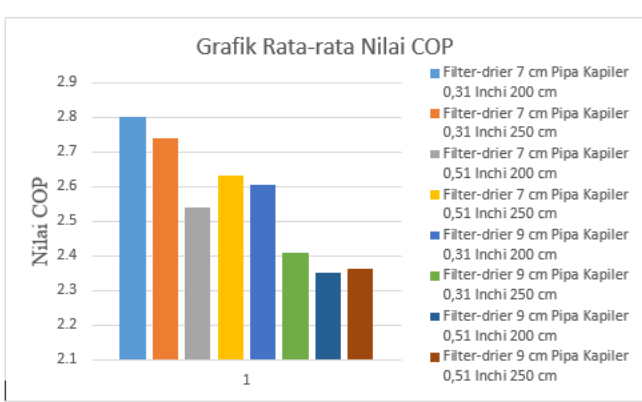

Gambar 3. Grafik Rata-rata Nilai COP

Dari gambar 3 telah ditunjukan bahwa semakin panjang dimensi alat ekspansi yang dipakai, nilai COP pada sistem akan semakin kecil. Hal ini terjadi karena adanya peningkatan nilai kerja kompresi pada mesin sehingga berpengaruh pula pada besaran nilai COP yang dimilikinya. Pemakaian filter-drier yang lebih kecil akan mengakibatkan jumlah refrigerant yang dimampatkan didalamnya menjadi lebih sedikit. Hal ini akan sangat berpengaruh terhadap terjadinya proses ekspansi pada pipa kapiler.

Pemakaian ukuran diameter pipa kapiler yang semakin kecil akan menjadikan proses ekspansi refrigerant di dalamnya lebih optimal. Ini terjadi karena semakin kecil diameter pipa kapiler yang dipakai maka akan semakin besar pula tekanan ekspansinya. Sehingga dengan demikian maka proses ekspansi refrigerant akan menjadi lebih optimal dan proses pendinginan kabin akan menjadi lebih cepat. Namun, apabila pipa kapiler yang dipakai dalam sistem semakin panjang maka akan mengakibatkan proses ekspansi menjadi lebih lama karena semakin jauhnya jarak yang harus ditempuh refrigerant untuk menuju ke evaporator. Untuk besaran konsumsi daya listrik pada sistem selama pengujian ditunjukan oleh tabel dibawah ini.

Tabel 2. Data Besaran Konsumsi Daya Listrik

\begin{tabular}{|c|c|c|c|c|c|c|c|c|}
\hline \multirow{4}{*}{$\begin{array}{c}\text { Menit } \\
\text { ke }\end{array}$} & \multicolumn{4}{|c|}{ Filter-drier 7cm } & \multicolumn{4}{c|}{ Filter-drier 9cm } \\
\cline { 2 - 9 } & $\begin{array}{c}\text { Pipa kapiler } \\
0,31 \text { Inchi }\end{array}$ & \multicolumn{2}{c|}{$\begin{array}{c}\text { Pipa kapiler } \\
0,51 \text { Inchi }\end{array}$} & \multicolumn{2}{c|}{$\begin{array}{c}\text { Pipa Kapiler } \\
0,31 \text { inchi }\end{array}$} & \multicolumn{2}{|c|}{$\begin{array}{c}\text { Pipa Kapiler } \\
0,51 \text { Inchi }\end{array}$} \\
\cline { 2 - 10 } & $\begin{array}{c}200 \\
\mathrm{~cm}\end{array}$ & $\begin{array}{c}250 \\
\mathrm{~cm}\end{array}$ & $\begin{array}{c}200 \\
\mathrm{~cm}\end{array}$ & $\begin{array}{c}250 \\
\mathrm{~cm}\end{array}$ & $\begin{array}{c}200 \\
\mathrm{~cm}\end{array}$ & $\begin{array}{c}250 \\
\mathrm{~cm}\end{array}$ & $\begin{array}{c}200 \\
\mathrm{~cm}\end{array}$ & $\begin{array}{c}250 \\
\mathrm{~cm}\end{array}$ \\
\hline 1 & 181.3 & 188.3 & 184.8 & 191.8 & 177.8 & 188.3 & 191.8 & 190.1 \\
\hline 5 & 181.3 & 186.6 & 188.3 & 191.8 & 184.8 & 188.3 & 184.8 & 191.8 \\
\hline 30 & 170.7 & 172.5 & 184.8 & 186.6 & 204.2 & 184.8 & 202.4 & 184.8 \\
\hline 35 & 169 & 172.5 & 188.3 & 183 & 170.2 & 181.3 & 197.1 & 179.5 \\
\hline 55 & 167.2 & 179.5 & 177.8 & 172.5 & 167.2 & 167.2 & 191.8 & 179.5 \\
\hline 60 & 167.2 & 174.2 & 184.8 & 174.2 & 170.7 & 179.5 & 190.1 & 172.5 \\
\hline $\begin{array}{l}\text { Rata- } \\
\text { Rata }\end{array}$ & 172.8 & 178.9 & 184.8 & 183.3 & 179.1 & 181.6 & 193 & 183.0 \\
\hline
\end{tabular}

Konsumsi daya listrik pada kompresor yang paling rendah terjadi pada penggunaan filter-drier 7 $\mathrm{cm}$ dan pipa kapiler berdiameter 0,31 inchi dengan panjang $200 \mathrm{~cm}$ yakni sebesar 172,8 VA. Sedangkan konsumsi daya listrik terbesar terjadi pada penggunaan filter-drier $9 \mathrm{~cm}$ dan pipa kapiler berdiameter 0,51 inchi dengan panjang $200 \mathrm{~cm}$. Adapun rata-rata konsumsi daya listrik pada sistem selama proses pengujian ditunjukan oleh grafik dibawah ini.

Rata-rata nilai konsumsi daya listrik pada penggunaan filter-drier $7 \mathrm{~cm}$ lebih kecil dibandingkan dengan penggunaan filter-drier $9 \mathrm{~cm}$. Hal ini juga disebabkan karena adanya perbedaan nilai COP dalam sistem. Nilai COP yang besar pada sistem menunjukan bahwa untuk melakukan proses pendinginan tidak memerlukan kerja kompresor yang besar. Sehingga hal ini juga berpengaruh pada konsumsi daya listrik kompresor.

Semakin panjang filter-drier yang digunakan dalam sistem, maka akan semakin tinggi pula konsumsi daya listriknya. Hal ini terjadi karena saat filter-drier yang dipakai berukuran lebih besar maka akan mengakibatkan refrigerant yang dapat dimampatkan didalamnya menjadi lebih banyak sehingga akan mempengaruhi terjadinya proses ekspansi pada refrigerant tersebut dan juga kerja kompresi pada sistem.

Selain itu penggunaan pipa kapiler dengan ukuran diameter yang lebih kecil juga akan mengakibatkan proses ekspansi refrigerant di dalamnya menjadi lebih optimal. Namun seiring bertambahnya panjang pipa kapiler yang dipakai, maka akan berdampak pada waktu terjadinya proses ekspansi refrigerant menjadi lebih lama karena jarak yang harus ditempuh untuk menuju evaporator menjadi lebih jauh. Saat proses pendinginan berlangsung lebih cepat, maka kerja kompresor pada sistem menjadi lebih ringan dan konsumsi daya listriknya menjadi lebih kecil.

\section{PENUTUP}

\section{Kesimpulan}

Berdasarkan hasil penelitian dan analisis yang telah dilakukan oleh penulis, dapat disimpulkan bahwa:

1. Apabila dimensi filter-drier dan pipa kapiler yang digunakan pada sistem semakin bertambah maka nilai COP yang dihasilkan oleh sistem akan semakin berkurang.

2. Semakin besar nilai COP yang dihasilkan oleh sistem akan menyebabkan konsumsi daya listriknya semakin berkurang.

\section{Saran}

Untuk mendapatkan nilai yang lebih akurat, cobalah untuk melakukan pengujian pada mesin dalam kondisi berbeban. 


\section{Ucapan Terima Kasih}

Saya mengucapkan terima kasih kepada pembimbing dan teman-teman yang telah membantu terlaksananya penelitian ini.

\section{DAFTAR PUSTAKA}

Daryanto. (2007). Merawat dan Memperbaiki Kulkas dan $A C$. Yogyakarta: Pustaka Widyawati.

Fuad, A. C. L., \& Putra, A. B. K. (2016). Studi Eksperimen Pengaruh Panjang Pipa Kapiler dan Variasi Beban Pendinginan pada. Jurnal Teknik ITS, 5(2).

Jakni. (2016). Metodologi Penelitian Eksperimen Bidang Pendidikan. Bandung: Alfabeta.

Oyedepo, S. O., Fagbenle, R. O., Babarinde, T. O., Odunfa, K. M., Leramo, R. O., Ohunakin, O. S., Ajayi, O. O., Babalola, P. O., Kilanko, O., Oyegbile, A. D., \& Lawson-Jack, D. (2017). A COMPARATIVE STUDY ON THE PERFORMANCE R600A AND LPG WITH VARYING REFRIGERANT CHARGE AND CAPILLARY TUBE LENGTH. International Journal of Energy for a Clean Environment, 18(4), 287-302.

Stoecker, W. F. \& Jones, J. W. (1992). Refrigerasi dan Pengkondisian Udara Edisi Kedua. In S. Hara (Ed.), Refrigeration And Air Conditioning Second Edition (p. 249). Jakarta: Erlangga.

Yang, S. J. (2017). Refrigerator. In United State Patent.

Zhang, W., Wang, Y., Lang, X., \& Fan, S. (2017). Performance analysis of hydrate-based refrigeration system. Energy Conversion and Management, $\quad 146, \quad 43-51$. https://doi.org/10.1016/j.enconman.2017.04.091 